\title{
Chester Step Test in Patients With COPD: Reliability and Correlation With Pulmonary Function Test Results
}

\author{
Anderson Alves de Camargo PT, Tatiana Justino PT, Carlos Henrique Silva de Andrade PT, \\ Carla Malaguti PT PhD, and Simone Dal Corso PT PhD
}

\begin{abstract}
BACKGROUND: The 5-stage Chester step test assesses aerobic capacity in healthy subjects. It has not been tested in patients with COPD. OBJECTIVE: To determine the reliability of the Chester step test in patients with COPD and correlation with pulmonary function test and exercise test results. METHODS: Thirty-two patients (mean \pm SD FEV $_{1} 46 \pm 15 \%$ of predicted) undertook 2 Chester step tests and two 6-min walk tests, on different days, in random order. A subgroup of 11 patients performed incremental cycle ergometry. RESULTS: Thirty-one patients performed stage 1 of the Chester step test. Nineteen patients performed stage 2 of the Chester step test. The number of steps was highly reproducible: $66 \pm 41$ steps vs $68 \pm 41$ steps. There was no difference in heart rate or $\mathrm{S}_{\mathrm{pO}_{2}}$ between the 2 Chester step tests at the peak of exercise or at the end of each stage. There was a significant correlation between number of steps and $\operatorname{FEV}_{1}(r=0.43, P=.02)$, and 6-min walk distance $(r=0.60, P=.001)$. Heart rate increased according to advanced stages of the Chester step test, up to $81 \pm 13 \%$ of predicted. There was a significant correlation between number of steps and peak heart rate $(r=0.55, P=.001)$. In the 11 patients who performed the incremental cycling test there was a significant correlation between number of steps and peak work load $(r=0.69, P=.02)$. In the 6 patients in whom oxygen uptake could be estimated from the Chester step test, oxygen uptake was higher than that measured at the peak of the cycling test $(30.8 \pm 5.1 \mathrm{~mL} / \mathrm{kg} / \mathrm{min}$ vs $17.4 \pm 4.5 \mathrm{~mL} / \mathrm{kg} / \mathrm{min}$, respectively, $P=.001)$. CONCLUSIONS: Despite being highly reproducible, the Chester step test had a very short duration in patients with COPD. The number of steps incremented in each stage seems to be too large for these patients. An adaptation of the Chester step test should be considered for patients with COPD. Key words: Chester step test; COPD; reliability; exercise test. [Respir Care 2011;56(7):995-1001. ( ) 2011 Daedalus Enterprises]
\end{abstract}

\section{Introduction}

Apart from pulmonary impairment, COPD leads to peripheral muscle dysfunction. ${ }^{1}$ The combination of pulmo-

\footnotetext{
Mr de Camargo and Ms Justino are affiliated with the School of Physiotherapy, Department of Health; Mr de Andrade is affiliated with the Rehabilitation Science Master's Program; and Dr Malaguti and Dr Dal Corso are affiliated with the Clinical Exercise Physiology Unit, Rehabilitation Science Master's Program, Nove de Julho University, Bairro Água Branca, São Paulo, Brazil.

Mr de Camargo was partly supported by a scientific initiation scholarship from the Fundação de Amparo à Pesquisa do Estado de São Paulo, São Paulo, Brazil. Ms Justino was partly supported by a scientific initiation scholarship from Conselho Nacional de Desenvolvimento Científico e Tecnológico, Brasília, Brazil.
}

nary and muscular disturbances contributes to reduced exercise capacity. ${ }^{2}$ The 6-min walk test and shuttle test are commonly used to assess functional capacity in patients with COPD. The step test is widely used in healthy subjects, and several step test protocols have been adapted to study various outcomes in cardiopulmonary diseases. ${ }^{3-13}$ The advantage of the step test over the 6-min walk test or

\footnotetext{
The authors have disclosed no conflicts of interest.

Correspondence: Simone Dal Corso PT PhD, Rehabilitation Science Master's Program, Universidade Nove de Julho, Av Francisco Matarazzo, 612-1 Andar, Bairro Água Branca, São Paulo/SP, CEP 05001-100, Brazil. E-mail: simonedc@uninove.br.
}

DOI: $10.4187 /$ respcare. 01047 


\section{Chester Step Test in Patients With COPD}

shuttle test is that the step test requires less space and therefore can be conducted in settings such as an intensive care unit, a physician's office, or at a home-based or inpatient rehabilitation program.

A wide variety of step tests have been described, with different cadences (self-paced or externally paced), step heights, and test durations. Because of the huge possibilities for adaptation, step tests can be used to assess physical capacity in patients with varied health status. The Chester step test was originally designed to assess aerobic capacity in healthy subjects, ${ }^{14}$ and was recently used to predict maximum oxygen uptake $\left(\dot{\mathrm{V}}_{\mathrm{O}_{2}}\right)$ and to evaluate the effectiveness of an exercise training program in patients with severe acute respiratory syndrome, ${ }^{12,13}$ but it has not been tested in COPD patients. In patients with COPD we evaluated the reliability of the Chester step test and its correlation with pulmonary function and exercise test results.

\section{Methods}

This study was approved by our institutional ethics committee, and all subjects gave written informed consent prior to inclusion.

\section{Patients}

We studied 32 (3 female) consecutive patients diagnosed with COPD. The inclusion criteria were $\mathrm{FEV}_{1}<70 \%$ of predicted, and clinical stability (no change in medication dosage in the preceding 4 weeks). We excluded patients with other pulmonary diseases (bronchiectasis and cystic fibrosis) or orthopedic or neurological conditions.

\section{Protocol}

On 2 different days, at least 48 hours apart, patients were randomized to perform either two 6-min walk tests (30 min rest between the tests) or two Chester step tests (30 min rest period between the tests).

\section{Spirometry}

We classified the severity of obstruction on spirometry results. ${ }^{15}$ Spirometry was performed at each visit, before the exercise tests, to check for similar pulmonary function on the 2 test days. Spirometry (CPF System, Medical Graphics, St Paul, Minnesota) was performed before and after bronchodilator ( $400 \mu \mathrm{g}$ of inhaled albuterol), per the American Thoracic Society/European Respiratory Society statement. ${ }^{16}$ We report the absolute and percent-of-predicted forced vital capacity and $\mathrm{FEV}_{1} \cdot{ }^{17}$

\section{Body Mass Index}

We categorized the subjects into the following body mass index (BMI) categories: underweight $<20.0 \mathrm{~kg} / \mathrm{m}^{2}$, normal weight $20.0-24.9 \mathrm{~kg} / \mathrm{m}^{2}$, overweight $>25.0-$ $29.9 \mathrm{~kg} / \mathrm{m}^{2}$, and obese $>30.0 \mathrm{~kg} / \mathrm{m}^{2} .{ }^{18}$

\section{6-Minute Walk Test}

Patients performed two 6-min walk distance according to American Thoracic Society recommendations. ${ }^{19}$ We measured heart rate (Polar Precision Performance, Kemple, Finland) and $\mathrm{S}_{\mathrm{pO}_{2}}$ (9500, Nonin, Plymouth, Minnesota) at rest before the test, half way through the test $(3 \mathrm{~min})$, and at the end of the test (6 min). We assessed dyspnea and leg fatigue at rest and immediately after finishing the test, with the modified Borg scale. ${ }^{20}$ If the patient was unable to walk for the full 6 minutes of the test, we recorded heart rate, $\mathrm{S}_{\mathrm{pO}_{2}}$, and walk distance at the point they stopped walking. We interrupted the test if $\mathrm{S}_{\mathrm{pO}_{2}}$ dropped below $88 \%$, then after a 30 -min rest period, we repeated the test with supplemental oxygen from a portable oxygen cylinder carried by the physiotherapist. We titrated the supplemental oxygen to maintain $\mathrm{S}_{\mathrm{pO}_{2}} \geq 88 \%$. We report the absolute and percent-of-predicted 6-min walk distances. ${ }^{21}$ We considered a 6 -min walk distance $<82 \%$ of predicted below normal. ${ }^{21}$ We selected the test with the higher 6-min walk distance for correlation with the Chester step test.

\section{Chester Step Test}

The Chester step test was performed on a $20 \mathrm{~cm}$ tall, single-step device with no handles. The Chester step test has 5 stages, each of 2 minutes duration (total test time $10 \mathrm{~min}$ ). The step cadence is set with a metronome, which starts at 15 steps/min and increases by 5 steps/min every 2 minutes: stage 1 (15 steps/min), stage 2 (20 steps/min), stage 3 ( 25 steps $/ \mathrm{min})$, stage 4 (30 steps/min), stage 5 (35 steps/min). Each subject underwent a step-test training session to determine if he or she was able to keep up the cadence set by the metronome. Before and every one minute during the training test we measured heart rate and $\mathrm{S}_{\mathrm{pO}_{2}}$, and the rules for supplemental oxygen were the same. The test was terminated either by the patient (because of dyspnea and/or leg fatigue) or by the physiotherapist if the patient was unable to maintain the cadence for 15 seconds. The subject scored his or her dyspnea and leg fatigue with the modified Borg scale at rest before the test and immediately after the test. The main outcome of the Chester step test is the total number of steps taken, and we recorded the test with the highest number of steps. This test was used for analyzing heart rate response during the test and for correlations with pulmonary function and exercise capacity tests. We estimated peak $\dot{\mathrm{V}}_{\mathrm{O}_{2}}$ during the Chester step 


\section{Chester Step Test in Patients With COPD}

test with the Chester Step Test Calculator (Assist Creative Resources, Wrexham, United Kingdom), ${ }^{22}$ which uses a regression line through submaximal heart-rate points that correspond to each test stage, up to a horizontal line that corresponds to the patient's predicted maximum heart rate (220 - age). A minimum of 2 exercise heart rates (ie, completing at least the first 2 stages of the Chester step test) is required. From the point that the regression line crosses the patient's predicted maximum heart rate, a perpendicular line is drawn down to the graph's $\mathrm{X}$ axis, which gives an estimated $\dot{\mathrm{V}}_{\mathrm{O}_{2}}$ (range $10-76 \mathrm{~mL} / \mathrm{kg} / \mathrm{min}$ ). In normal subjects the accuracy of this estimate is approximately $5-15 \% .23$

\section{Cardiopulmonary Exercise Testing}

A subset of 11 of the 18 patients who did not require supplemental oxygen during the step testing, did incremental exercise testing on an electromagnetically braked cycle ergometer (CPE 2000, Medical Graphics, St Paul, Minnesota), during which we measured pulmonary gas exchange (MGC-CPX, Medical Graphics Corporation, St Paul, Minnesota). We continuously increased the work rate by $5-15$ watts/min so that the ramp duration was $>8 \mathrm{~min}$ and $<12 \mathrm{~min}$. We considered a reduced aerobic capacity a peak $\dot{\mathrm{V}}_{\mathrm{O}_{2}}<70 \%$ of predicted. ${ }^{24}$ We compared the measured peak $\dot{\mathrm{V}}_{\mathrm{O}_{2}}$ during cycling to the estimated peak $\dot{\mathrm{V}}_{\mathrm{O}_{2}}$ in the Chester step test. For this part of the study we analyzed 6 patients, because to estimate $\dot{\mathrm{V}}_{\mathrm{O}_{2}}$ from the Chester step test it is necessary to complete at least the first 2 stages of the Chester step test and the subject must be $\leq 70$ years old. ${ }^{21}$

\section{Statistical Analysis}

We report parametric data as mean $\pm \mathrm{SD}$, and nonparametric as median and range values. Differences in heart rate, $\mathrm{S}_{\mathrm{pO}_{2}}$, and number of steps were determined via paired- $t$ test. To determine the test/retest reliability of the measured variables between the Chester step tests we calculated the intraclass correlation coefficients with oneway analysis of variance. An intraclass correlation coefficient of $0.80-1.0$ is considered excellent reliability, $0.60-$ 0.79 is good reliability, and $<0.60$ is low reliability. We also used the Bland-Altman method to analyze the reliability of the number of steps. We used the step test with the higher number of steps for the correlations analysis. We calculated the Pearson correlation coefficients to analyze the relationship between number of steps and $\mathrm{FEV}_{1}$, forced vital capacity, heart rate and oxygen saturation at peak exercise during the Chester step test, and 6-min walk distance. We used the paired $t$ test to compare the estimated and measured $\dot{\mathrm{V}}_{\mathrm{O}_{2}}$ values. The probability of type 1 error was set at 5\% $(P<.05)$. The analyses were per-
Table 1. Subjects $(n=32)$

\begin{tabular}{|c|c|c|}
\hline & Mean \pm SD & $\begin{array}{c}\text { Percent } \\
\text { Predicted }\end{array}$ \\
\hline Age (y) & $69.9 \pm 9.0$ & NA \\
\hline BMI $\left(\mathrm{kg} / \mathrm{m}^{2}\right)$ & $25.9 \pm 15.1$ & NA \\
\hline $\mathrm{FEV}_{1}(\mathrm{~L})$ & $1.2 \pm 0.4$ & $46 \pm 15$ \\
\hline $\mathrm{FVC}(\mathrm{L})$ & $2.8 \pm 0.8$ & $81 \pm 16$ \\
\hline $\mathrm{FEV}_{1} / \mathrm{FVC}$ & $43.6 \pm 10.4$ & NA \\
\hline 6-min walk distance $(\mathrm{m})$ & $398 \pm 110$ & $69 \pm 20$ \\
\hline \multicolumn{3}{|l|}{ Cycle Ergometry $(n=11)$} \\
\hline Peak work load (watts) & $61.2 \pm 24.7$ & $43 \pm 14$ \\
\hline Peak $\dot{\mathrm{V}}_{\mathrm{O}_{2}}(\mathrm{~L} / \mathrm{min})$ & $1.15 \pm 0.38$ & $56 \pm 13$ \\
\hline $\begin{array}{l}\mathrm{NA}=\text { not applicable } \\
\mathrm{BMI}=\text { body mass index } \\
\mathrm{FVC}=\text { forced vital capacity } \\
\mathrm{V}_{\mathrm{O}_{2}}=\text { oxygen uptake }\end{array}$ & & \\
\hline
\end{tabular}

formed with statistics software (SPSS 14.0, SPSS, Chicago, Illinois).

\section{Results}

As expected, all the subjects had reduced pulmonary function (Table 1). Twenty-seven patients had moderate to severe obstruction, and 5 had very severe obstruction. One subject was underweight, 17 were normal weight, 5 were overweight, and 9 were obese. Twenty patients had a 6-min walk distance $<82 \%$ of predicted. Peak aerobic capacity was below the predicted values: 8 out of the 11 cycle ergometry subjects had peak $\dot{\mathrm{V}}_{\mathrm{O}_{2}}<70 \%$ of predicted.

\section{Reliability of the Chester Step Test}

The subjects presented similar pulmonary function between the first and the second Chester step test: $\mathrm{FEV}_{1} 1.18 \pm 0.36 \mathrm{~L}$ vs $1.17 \pm 0.36 \mathrm{~L}$, respectively, and forced vital capacity $2.84 \pm 0.77 \mathrm{~L}$ vs $2.90 \pm 0.77 \mathrm{~L}$, respectively. Between the tests there was no significant difference in heart rate, $\mathrm{S}_{\mathrm{pO}_{2}}$, dyspnea score, or leg fatigue score measured at rest (Table 2).

All the patients could follow the cadence imposed during the Chester step test. Eighteen of the 32 patients needed supplemental oxygen $(4 \pm 2 \mathrm{~L} / \mathrm{min})$. Considering the best performance on the Chester step test, 31 patients completed stage 1, 19 completed stage 2, 7 completed stage 3, and 1 patient completed stage 4 and the first minute of stage 5 . Twelve patients had the test interrupted by the physiotherapist because the patient could not maintain the cadence. Twenty patients asked to stop the test because of dyspnea (2 patients), leg fatigue (8 patients), or dyspnea plus leg fatigue (10 patients). Table 2 shows the median dyspnea and leg fatigue scores at peak exercise during the step test. A similar number of patients performed best on 


\section{Chester Step Test in Patients With COPD}

Table 2. Chester Step Test Results

\begin{tabular}{|c|c|c|c|c|}
\hline & $\begin{array}{l}\text { Chester Step } \\
\text { Test } 1\end{array}$ & $\begin{array}{c}\text { Chester Step } \\
\text { Test } 2\end{array}$ & $\begin{array}{l}\text { Intraclass Correlation } \\
\text { Coefficient* }\end{array}$ & $\begin{array}{l}95 \% \mathrm{CI} \text { of Intraclass } \\
\text { Correlation Coefficient }\end{array}$ \\
\hline At Rest Before Test & $(n=32)$ & $(n=32)$ & & \\
\hline Heart rate (beats/min) & $86 \pm 14$ & $83 \pm 13$ & 0.88 & $0.78-0.94$ \\
\hline $\mathrm{S}_{\mathrm{pO}_{2}}(\%)$ & $95 \pm 2$ & $95 \pm 2$ & 0.85 & $0.77-0.93$ \\
\hline Dyspnea score, median (range) & $0.5(0-2)$ & $0.5(0-3)$ & 0.92 & $0.84-0.96$ \\
\hline Leg fatigue score, median (range) & $0.5(0-3)$ & $0.5(0-3)$ & 0.91 & $0.81-0.96$ \\
\hline Stage 1 & $(n=31)$ & $(n=31)$ & & \\
\hline Heart rate (beats/min) & $109 \pm 15$ & $108 \pm 16$ & 0.94 & $0.88-0.96$ \\
\hline $\mathrm{S}_{\mathrm{pO}_{2}}(\%)$ & $92 \pm 4$ & $92 \pm 4$ & 0.83 & $0.65-0.92$ \\
\hline Stage 2 & $(n=17)$ & $(n=19)$ & & \\
\hline Heart rate (beats/min) & $119 \pm 13$ & $116 \pm 14$ & 0.94 & $0.84-0.98$ \\
\hline $\mathrm{S}_{\mathrm{pO}_{2}}(\%)$ & $92 \pm 3$ & $91 \pm 4$ & 0.80 & $0.42-0.93$ \\
\hline Stage 3 & $(n=7)$ & $(n=7)$ & & \\
\hline Heart rate (beats/min) & $136 \pm 8$ & $132 \pm 11$ & 0.87 & $0.77-0.87$ \\
\hline $\mathrm{S}_{\mathrm{pO}_{2}}(\%)$ & $94 \pm 2$ & $93 \pm 2$ & 0.95 & $0.65-0.99$ \\
\hline Stage 4 & $(n=1)$ & $(n=1)$ & & \\
\hline Heart rate (beats/min) & 148 & 150 & NA & NA \\
\hline $\mathrm{S}_{\mathrm{pO}_{2}}(\%)$ & 95 & 92 & NA & NA \\
\hline Peak Step-Test Exercise & $(n=32)$ & $(n=32)$ & & \\
\hline \multicolumn{5}{|l|}{ Heart Rate } \\
\hline (beats/min) & $120 \pm 17$ & $121 \pm 20$ & 0.95 & $0.89-0.97$ \\
\hline (\% predicted) & $80 \pm 10$ & $80 \pm 13$ & 0.95 & NA \\
\hline $\mathrm{S}_{\mathrm{pO}_{2}}(\%)$ & $92 \pm 4$ & $91 \pm 4$ & 0.91 & $0.81-0.96$ \\
\hline Dyspnea, median (range) & $4(1-10)$ & $4(0-9)$ & 0.90 & $0.79-0.95$ \\
\hline Leg fatigue, median (range) & $4(2-10)$ & $5(0-9)$ & 0.86 & $0.71-0.94$ \\
\hline Exercise time (s) & $229 \pm 106$ & $228 \pm 113$ & 0.98 & $0.98-0.99$ \\
\hline Number of steps & $66 \pm 41$ & $68 \pm 41$ & 0.99 & $0.97-0.99$ \\
\hline \multicolumn{5}{|c|}{$\begin{array}{l}\text { values are mean } \pm \text { SD. } \\
* \text { All the intraclass correlation coefficients are statistically significant. } \\
\mathrm{NA}=\text { not applicable }\end{array}$} \\
\hline
\end{tabular}

the first versus the second Chester step test (16 and 15 patients, respectively).

Between the 2 Chester step tests there were no significant differences in heart rate or $\mathrm{S}_{\mathrm{pO}_{2}}$ at peak step-test exercise or at the end of each stage, and the reliability analysis revealed high intraclass correlation coefficients (see Table 2). The Bland-Altman analysis (Fig. 1) of the number of steps in the first versus the second Chester step test showed a mean difference of -1.1 steps/min (limits of agreement -20.2 to 17.9 steps).

There was a moderate correlation between number of steps and $\mathrm{FEV}_{1}(\mathrm{r}=0.43, P=.02)$, and a stronger relationship between number of steps and 6-min walk distance $(\mathrm{r}=0.60, P=.001)$. Heart rate increased progressively in the stages of the Chester step test, to $81 \pm 13 \%$ of predicted at peak exercise (see Table 2). There was a significant correlation between number of steps and peak heart rate $(\mathrm{r}=0.55, P=.001)$. There was no significant correlation between number of steps and $\mathrm{S}_{\mathrm{pO}_{2}}$.

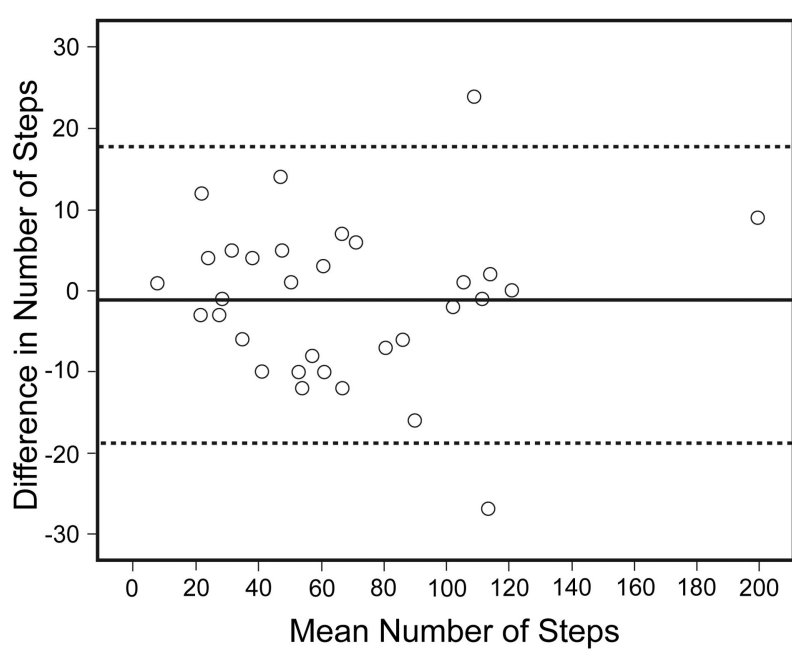

Fig. 1. Bland-Altman plot of number of steps versus between-test difference in number of steps. The solid horizontal line represents the mean bias. The dashed horizontal lines represent 1.96 standard deviations. 


\section{Chester Step Test in Patients With COPD}

In the 11 patients $\left(\mathrm{FEV}_{1} 45 \pm 17 \%\right.$ of predicted) who performed the incremental cycling test the peak work load was $61.2 \pm 24.7$ watts ( $43 \pm 14 \%$ of predicted), and there was a significant correlation with the number of steps ( $\mathrm{r}=0.69, P=.02$ ). Only 6 of the cycling-test patients $\left(\mathrm{FEV}_{1} 41 \pm 16 \%\right.$ of predicted) met the criteria required to estimate $\dot{\mathrm{V}}_{\mathrm{O}_{2}}$ from the Chester step test, and it was higher than the measured $\dot{\mathrm{V}}_{\mathrm{O}_{2}}$ at the peak of the cycling test $(30.8 \pm 5.1 \mathrm{~mL} / \mathrm{kg} / \mathrm{min}$ vs $17.4 \pm 4.5 \mathrm{~mL} / \mathrm{kg} / \mathrm{min}$, respectively, $P=.001)$.

\section{Discussion}

The similarity between Chester step test trials for heart rate and $\mathrm{S}_{\mathrm{pO}_{2}}$ at each stage and at peak exercise, total number of steps, and dyspnea and leg fatigue indicates that the Chester step test is reproducible in COPD patients, and significantly correlates with $\mathrm{FEV}_{1}, 6$-min walk distance, and peak work load during cycling ergometry.

There have been few studies of step tests in patients with chronic pulmonary diseases. In patients with COPD, Swinburn et $\mathrm{al}^{4}$ found large inter-subject differences in performance (range 14-126 steps), which is much greater than we observed in our study (limits of agreement -20.2 to 17.9 steps). Increments in the work rate during the Chester step test might improve the reproducibility, because the work intensity influences symptom magnitude (dyspnea and fatigue) much more than does the test duration. ${ }^{25}$ The cadence changes during the Chester step test determine the increase in the work intensity, which precipitates the perceived exertion, leading patients to discontinue the test at a similar stage to that achieved in the previous test. Patients with cystic fibrosis ${ }^{5}$ and exerciseinduced asthma ${ }^{7}$ showed better reproducibility in a step test than we observed. Both of the latter studies used a 3-min step test, and though some of the children could continue the test, it was interrupted when the established end-time was reached, and we suspect that the short test duration probably contributed to the excellent reproducibility.

Despite the differences between the step test used by Swinburn et al and the Chester step test (step height $25 \mathrm{~cm}$ vs $20 \mathrm{~cm}$, respectively, and cadence constant vs incremental, respectively), the patients were able to tolerate very similar and short test durations. A previous study found that stair climbing resulted in prolonged lung hyperinflation, a higher blood lactate, and greater dyspnea than walking in patients with severe COPD. ${ }^{26}$ The findings were similar in a comparison of cycling and walking. ${ }^{27}$ In the present study the physiologic mechanisms underlying the very short duration of the Chester step test in patients with COPD could not be explored because gas-exchange variables were not measured.
The strength of correlation between number of steps and pulmonary function was moderate and very similar to the results from comparisons of 6-min walk distance and shuttle test. ${ }^{28-30}$ Furthermore, the relationship we observed between the Chester step test steps and 6-min walk distance was comparable to the relationship previously found between 6-min walk distance and shuttle walk distance. ${ }^{31}$ In addition, the correlation we observed between number of steps and peak work load in the cycling test $(r=0.69)$ was similar to that reported in studies of peak work load in the 6-min walk test versus the shuttle test. ${ }^{32,33}$ Therefore the number of steps climbed in the Chester step test can be representative of functional performance, and, when tests that require long corridors are unfeasible, step tests may be an alternative. However, further studies are needed to establish a better incremental pattern for patients with chronic respiratory diseases, once it has been demonstrated that variations of incremental size affect exercise time in patients with COPD. ${ }^{34,35}$ Then, when large increments are used, the test certainly will be brief. Despite the consistent results in repeated Chester step tests in our patients, we speculate that reducing the work load increment would be appropriate for patients with COPD, to achieve a total exercise time of $8-10 \mathrm{~min}$, which is efficient and useful for assessing cardiopulmonary responses. ${ }^{36}$

We found no significant correlation between number of steps and $\mathrm{S}_{\mathrm{pO}_{2}}$ at peak exercise. This finding may be explained by the combination of a short test time and the use of supplemental oxygen during the Chester step test. Maximum heart rate peak exercise in the Chester step test corresponded to $80 \%$ of predicted maximum, which is equivalent to that observed at peak exercise in both the 6-min walk test ${ }^{33,37}$ and the shuttle test. ${ }^{33}$ This result was expected, because the Chester step test is a 2-min incremental exercise test that elicits a graded cardiovascular response (see Table 2).

Based on heart rate achieved in each Chester step test stage it is possible to estimate the peak $\dot{\mathrm{V}}_{\mathrm{O}_{2}} \cdot{ }^{22} \mathrm{We}$ found a huge difference between the estimated and measured $\dot{\mathrm{V}}_{\mathrm{O}_{2}}$. In addition to the inaccuracy inherent in estimating peak $\dot{\mathrm{V}}_{\mathrm{O}_{2}}$ from Chester step test results in healthy subjects, ${ }^{38}$ abnormal heart-rate responses during the Chester step test can also affect this $\dot{\mathrm{V}}_{\mathrm{O}_{2}}$ estimate. Debigaré et al have found that a faster work rate increment led to a right shift of the relationship between heart rate and work rate. ${ }^{34}$ Therefore, lower heart rates are observed during increase in work rate incremental rate.

In addition, patients with COPD presented with a slower response of heart rate during exercise than did normal subjects. ${ }^{39}$ Although this finding has been described in cycling tests, we speculate that the same effect could be observed in step tests, especially if large increments are imposed. Even though baseline heart rate is not considered as a point in the regression line to estimate $\dot{\mathrm{V}}_{\mathrm{O}_{2}}$ from 


\section{Chester Step Test in Patients With COPD}

Chester step test, a high baseline heart rate can also contribute to a low change in heart rate with exercise progression. This possible overestimation of $\dot{\mathrm{V}}_{\mathrm{O}_{2}}$ from Chester step test was also speculated for patients with severe acute respiratory syndrome explained by a higher baseline heart rate and delayed increase in heart rate during the test. ${ }^{13}$

\section{Limitations}

First, our patients completed just 2 Chester step tests, and a similar number of patients achieved their best Chester step test score in their first and second test. Therefore, we do not know how many Chester step tests are necessary to achieve the best performance. Second, the sample size we used to compare the estimated and measured $\dot{\mathrm{V}}_{\mathrm{O}_{2}}$ was small $(n=6)$. In addition, patients were not able to complete all the stages of the Chester step test, which may have limited the accuracy of the peak $\dot{\mathrm{V}}_{\mathrm{O}_{2}}$ estimates. A larger-sample study with measurement of pulmonary gas exchange in patients with COPD is needed to verify the cardiopulmonary responses during the Chester step test. Finally, we used the number of steps as an estimation of work performed in the Chester step test, ${ }^{8}$ but the use of this outcome as a surrogate for work must be validated for the Chester step test in patients with COPD.

\section{Conclusions}

The Chester step test is highly reproducible in patients with COPD, but the Chester step test seems to be a difficult protocol for patients with chronic respiratory disease, probably because of an initial cadence that is too high and a work-load increment that is too large for these patients. Therefore, an adaptation of the Chester step test for patients with COPD should be tested.

\section{REFERENCES}

1. Hill K, Goldstein RS. Limited functional performance in chronic obstructive pulmonary disease: nature, causes and measurement. COPD 2007;4(3):257-261.

2. Celli BR, Cote CG, Marin JM, Casanova C, Montes de Oca M, Mendez RA, et al. The body-mass index, airflow obstruction, dyspnea, and exercise capacity index in chronic obstructive pulmonary disease. N Engl J Med 2004;350(10):1005-1012.

3. Nicolaescu V, Racoveanu C, Manicatide M. Effects of exercise on practocol-treated asthmatic patients. Eur J Clin Pharmacol 1973; 6(1):3-8.

4. Swinburn CR, Wakefield JM, Jones PE. Performance, ventilation, oxygen consumption in three different types of exercise test in patients with chronic obstructive pulmonary disease. Thorax 1985; 40(8):581-586.

5. Balfour-Lynn IM, Prasad SA, Laverty A, Whitehead BF, Dinwiddie R. A step in the right direction: assessing exercise tolerance in cystic fibrosis. Pediatr Pulmonol 1998;25(4):278-284.

6. Kramer MR, Krivourk V, Lebzelter J, Liani M, Fink G. Quantitative 15 steps exercise oximetry as a marker of disease severity in patients with chronic obstructive pulmonary disease. Isr Med Assoc J 1999; 1(3):165-168.

7. Tancredi G, Quattrucci S, Scalercio F, De Castro G, Zicari AM, Bonci E, et al. 3-min step test and treadmill exercise for evaluating exercise-induced asthma. Eur Respir J 2004;23(4):569-574.

8. Dal Corso S, Duarte SR, Neder JA, Malaguti C, de Fuccio MB, de Castro Pereira CA, Nery LE. A step test to assess exercise-related oxygen dessaturation in interstitial lung disease. Eur Respir J 2007; 29(2):330-336.

9. Stephan S, de Castro Pereira CA, Coletta EM, Ferreira RG, Otta JS, Nery LE. Oxygen dessaturation during a 4-minute step test: predicting survival in idiopathic pulmonary fibrosis. Sarcoidosis Vasc Diffuse Lung Dis 2007;24(1):70-76.

10. Rusanov V, Shitrit D, Fox B, Amital A, Peled N, Kramer MR. Use of the 15-steps climbing exercise oximetry test in patients with idiopathic pulmonary fibrosis. Respir Med 2008;102(7):1080-1088.

11. Shitrit D, Rusanov V, Peled N, Amital A, Fuks L, Kramer MR. The 15-step oximetry test: a reliable tool to identify candidates for lung transplantation among patients with idiopathic pulmonary fibrosis. J Heart Lung Transplant 2009;28(4):328-333.

12. Lau HM, Ng GY, Jones AY, Lee EW, Siu EH, Hui DS. A randomised controlled trial of the effectiveness of an exercise training program in patients recovering from severe acute respiratory syndrome. Aust J Physiother 2005;51(4):213-219.

13. Lau HM, Lee EW, Wong CN, Ng GY, Jones AY, Hui DS. The impact of severe acute respiratory syndrome on the physical profile and quality of life. Arch Phys Med Rehabil 2005;86(6):1134-1140.

14. Sykes K. Capacity assessment in the workplace: a new step test. Occup Health 1995;47(1):20-22.

15. Rabe KF, Hurd S, Anzueto A, Barnes PJ, Buist SA, Calverley P, et al. Global strategy for the diagnosis, management, and prevention of chronic obstructive pulmonary disease: GOLD executive summary. Am J Respir Crit Care Med 2007;176(6):532-555.

16. Pellegrino R, Viegi G, Brusasco V, Crapo RO, Burgos F, Casaburi $\mathrm{R}$, et al. Interpretative strategies for lung function tests. Eur Respir J 2005;26(5):948-968.

17. Pereira CAC, Barreto SP, Simões JG. Valores de referência para espirometria em uma amostra da população brasileira adulta. J Pneumol 1992;18(1):10-22. Article in Portugese.

18. World Health Organization. The world health report 2002: reducing risks, promoting health life. Geneva: World Health Organization; 2002.

19. American Thoracic Society. ATS statement: guidelines for the sixminute walk test. Am J Respir Crit Care Med 2002;166(1):111-117.

20. Wilson RC, Jones PW. A comparison of the visual analogue scale and modified Borg scale for the measurement of dyspnoea during exercise. Clin Sci 1989;76(3):277-282.

21. Troosters T, Gosselink R, Decramer M. Six minute walking distance in healthy elderly subjects. Eur Respir J 1999;14(2):270-274.

22. Sykes K. The Chester step test, 2nd edition. Liverpool, UK: Assist Creative Resources; 2005.

23. Sykes K, Roberts A. The Chester step test-a simple yet effective tool for the prediction of aerobic capacity. Physiotherapy 2004;90(4): 183-188.

24. Neder JA, Nery LE, Bagatin E, Lucas SR, Anção MS, Sue DY. Differences between remaining ability and loss of capacity in maximum aerobic impairment. Braz J Med Biol Res 1998;31(5):639646.

25. Kearon MC, Summers E, Jones NL, Campbell EJ, Killian KJ. Effort and dyspnoea during work of varying intensity and duration. Eur Respir J 1991;4(8):917-925.

26. Dreher M, Walterspacher S, Sonntag F, Prettin S, Kabitz HJ, Windisch W. Exercise in severe COPD: is walking different from stairclimbing? Respir med 2008;102(6):912-918. 


\section{Chester Step Test in Patients With COPD}

27. Palange P, Forte S, Onorati P, Manfredi F, Serra P, Carlone S. Ventilatory and metabolic adaptations to walking and cycling in patients with COPD. J Appl Physiol 2000;88(5):1715-1720.

28. Wijkstra PJ, TenVergert EM, van der Mark TW, Postma DS, Van Altena R, Kraan J, Köeter GH. Relation of lung function, maximal inspiratory pressure, dyspnoea and quality of life with exercise capacity in patients with chronic obstructive pulmonary disease. Tho$\operatorname{rax}$ 1994;49(5):468-472.

29. Marin JM, Carrizo SJ, Gascon M, Sanchez A, Gallego B, Celli BR. Inspiratory capacity, dynamic hyperinflation, breathlessness, and exercise performance during the 6-minute-walk-test in chronic obstructive pulmonary disease. Am J Respir Crit Care Med 2001;163(6): 1395-1399.

30. Steiner MC, Singh SJ, Morgan MD. The contribution of peripheral muscle function to shuttle walking performance in patients with chronic obstructive pulmonary disease. J Cardiopulm Rehabil 2005; 25(1):43-49.

31. Singh SJ, Morgan MD, Scott S, Walters D, Hardman AE. Development of a shuttle walking test of disability in patients with chronic airways obstruction. Thorax 1992;47(12):1019-1024.

32. Luxton N, Alinson JA, Wu J, Mackey MG. Relationship between field walking tests and incremental cycle ergometry in COPD. Respirology 2008;13(6):856-862.
33. Turner SE, Eastwood PR, Cecins N, Hillman D, Jenkins SC. Physiologic responses to incremental and self-paced exercise in COPD: a comparison of three tests. Chest 2004;126(3):766-773.

34. Debigaré R, Maltais F, Mallet M, Casaburi R, LeBlanc P. Influence of work rate incremental rate on the exercise responses in patients with COPD. Med Sci Sports Exerc 2000;32(8):1365-1368.

35. Gläser S, Lodziewski S, Koch B, Opitz CF, Völzke H, Ewert R. Influence of the incremental step size in work rate on exercise response and gas exchange in patients with pulmonary hypertension. BMC Pulm Med 2008;8(3):1-6.

36. American Thoracic Society; American College of Chest Physicians. ATS/ACCP statement on cardiopulmonary exercise testing. Am J Respir Crit Care Med 2003;167(2):211-277.

37. Troosters T, Vilaro J, Rabinovich R, Casas A, Barberà JA, Rodrigues-Roisin R, Roca J. Physiological responses to the 6-min walk test in patients with chronic obstructive pulmonary disease. Eur Respir J 2002;20(3):564-569.

38. Buckley JP, Sim J, Eston RG, Hession R, Fox R. Reliability and validity of measures taken during the Chester step test to predict aerobic power and to prescribe aerobic exercise. Br J Sports Med 2004;38(2):197-205

39. Nery LE, Wasserman K, Andrews JD, Huntsman DJ, Hansen JE, Whipp BJ. Ventilatory and gas exchange kinetics during exercise in chronic airways obstruction. J Appl Physiol 1982;53(6):1594-1602. 